\section{Pulmonary vascular volumes and airways obstruction in SCD patients}

Dear Editor

We read with interest the recent paper by Chaudry et $a l^{1}$ in which the authors describe an obstructive ventilatory defect in children with sickle cell disease (SCD) which was not linked to bronchial hyperresponsiveness, as assessed by methacholine challenge testing, or to eosinophillic inflammation. Their results further demonstrate that the airflow obstruction seen in children with SCD may not solely be due to asthma. Indeed, in children with SCD, we have shown that pulmonary capillary blood volume is increased compared to matched controls, and is correlated with airflow obstruction as assessed by impulse oscillometry. ${ }^{2}$ In SCD adults, we previously demonstrated that prominent central vessels were often present on high-resolution CT (HRCT) with correlations between reductions in $\mathrm{FEV}_{1}$ and FVC and prominence of central vessels. ${ }^{3}$ We have subsequently carried out a detailed study of vascular abnormalities on HRCT using two quantitative measures of vessel dilatation (the segmental artery-bronchus $(\mathrm{A} / \mathrm{B})$ ratio and the total cross-sectional area of all pulmonary vessels less than $5 \mathrm{~mm}$ in diameter $(\mathrm{CSA}<5 \mathrm{~mm} \%)$. Increases in segmental $\mathrm{A} / \mathrm{B}$ ratio and $\mathrm{CSA}<5 \mathrm{~mm} \%$ were independently linked to reductions in $\mathrm{FEV}_{1}, \mathrm{VC}$ and $\mathrm{FEF}_{25-75}$, and to increased respiratory system resistance and RV:TLC. Small vessel dimensions correlated with reduced haemoglobin concentration and oxygen saturation and increased cardiac output, lactate dehydrogenase level, reticulocyte count and serum bilirubin, suggesting interactions between haemolysis, anaemia, hypoxia and pulmonary function abnormalities. ${ }^{4}$ We, therefore, suggest that alterations in pulmonary vascular volumes due to anaemia in SCD patients contribute to their lung function abnormalities.

\section{Anne Greenough, ${ }^{1,2}$ Alan Lunt ${ }^{1,2}$}

${ }^{1}$ Division of Asthma, Allergy and Lung Biology, MRC-Asthma UK Centre in Allergic Mechanisms of Asthma, King's College London, London, UK ${ }^{2}$ NIHR Biomedical Research Centre at Guy's and St Thomas' NHS Foundation Trust and King's College London, London, UK

Correspondence to Professor Anne Greenough, NICU, 4th Floor Golden Jubilee Wing, King's College Hospital, Denmark Hill, London SE5 9RS, UK; anne.greenough@kcl.ac.uk

Contributors $A G$ and $A L$ wrote the letter.

Competing interests None.

Provenance and peer review Not commissioned; internally peer reviewed.

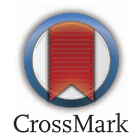

To cite Greenough A, Lunt A. Thorax 2014;69:1051.

Received 12 June 2014

Accepted 23 June 2014

Published Online First 15 July 2014

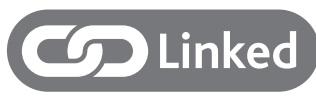

http://dx.doi.org/10.1136/thoraxinl-2013-204464

http://dx.doi.org/10.1136/thoraxjnl-2014-205926

Thorax 2014;69:1051.

doi:10.1136/thoraxjnl-2014-205886

\section{REFERENCES}

1 Chaudry RA, Rosenthal M, Bush A, et al. Reduced forced expiratory flow but not increased exhaled nitric oxide or airway responsiveness to methacholine characterises paediatric sickle cell airway disease. Thorax 2014;69:580-5.

2 Wedderburn CJ, Rees D, Height S, et al. Airways obstruction and pulmonary capillary blood volume in children with sickle cell disease. Pediatr Pulmonol 2014;49:716-22.

3 Sylvester KP, Desai SR, Wells AU, et al. Computed tomography and pulmonary function abnormalities in sickle cell disease. Eur Respir J 2006;28: 832-8.

4 Lunt A, Desai SR, Wells AU, et al. Pulmonary function, $\mathrm{CT}$ and echocardiographic abnormalities in sickle cell disease. Thorax 2014:69:746-51. 